\title{
Impact of UPFC on Distance Relay: A Case Study
}

\author{
Prachi Tripathi, Miss Sudeshna Ghosh, \\ Deptt. of Electrical \& Electronics Engg. LNCTE, Bhopal (M.P) India
}

\begin{abstract}
In the power transmission system FACT controller is incorporated in the transmission line in order to increase power transfer capability as well as reactive power control. The FACT devices which combine the feature of shunt fact devices and series fact devices are considered i.e. UPFC (Unified power flow controller) which address the issue of adaptive protection of a transmission line where this device is located at the different position of transmission line like middle of the transmission line, sending end and receiving end of transmission line. Design and simulating the UPFC incorporated in transmission line is done in PSCAD/ EMTDC software. The impact of UPFC on the distance relay is described by impedance trajectory, disturbance in voltage and current and apparent impedance is carried out in the presence of UPFC for different fault calculation.

Index Terms: UPFC, PSCAD/EMTDC, FACTS, Apparent Impedance.
\end{abstract}

\section{Introduction}

The development of power electronics applications in power systems provides great benefits in technical or economical terms. Applying FACTS series compensators is one of the electronics controllers that enhanced power transfer capability, transient stability and damping of power transfer through transmission lines. However, one of the difficulties of having FACTS compensation is that the calculation of capacitor voltage drop cannot be estimated using conventional methods [1] [2].

The operation of FACTS devices introduces harmonics and non linearity's to the power system, which adversely affect the protection systems and the fault detection methods. Transmission power systems today are complex networks which include long transmission lines necessary to transport energy from large generation units to bulk consumption loads. The compensation of transmission lines is a mature technique which can greatly increases the amount of power to be transported. The improvements in the field of power electronics have had major impact on the development of the concept itself. These controllers are based on voltage source converters and include devices such as Static Var Compensators (SVCs), Static Synchronous Compensators (STATCOMs), Thyristor Controlled Series Compensators (TCSCs), the Static Synchronous Series Compensators (SSSCs), and the Unified Power Flow Controllers (UPFCs).

The UPFC is the most versatile and complex of the FACTS devices, combining the features of the STATCOM and the SSSC. The UPFC can provide simultaneous control of all basic power system parameters, viz., transmission voltage, impedance and phase angle. It is recognized as the most Sophisticated power flow controller currently, and probably the most expensive one.

We know that the compensating equipment should be installed in transmission lines longer than 100 $\mathrm{Km}$. The compensating factor, which is the ratio between the reactance of the compensating element and the total reactance of the transmission line, ranges between a minimum of $20 \%-40 \%$ up to a limit of $75 \%$. The selection of this compensating factor heavily depends on the network configuration, the system security and stability criteria.

Distance protection relays for non -compensated lines are not normally designed for non linear line impedance changes. Such relay should not be used in a line compensated environment. In such context, out of using high-cost pilot protection, solutions fingers to develop new algorithm fully committed to correctly detect faults and distance under the conditions imposed by the transient behavior of voltage and line current fed to the distance relay [1-8].

\section{Unified Power Flow Controller}

The basic components of the UPFC are two voltage source inverters (VSIs) sharing a common dc storage capacitor, and connected to the power system through coupling transformers. One VSI is connected to in shunt to the transmission system via a shunt transformer, while the other one is connected in series through a series transformer. A basic UPFC functional scheme is shown in Fig.1. 


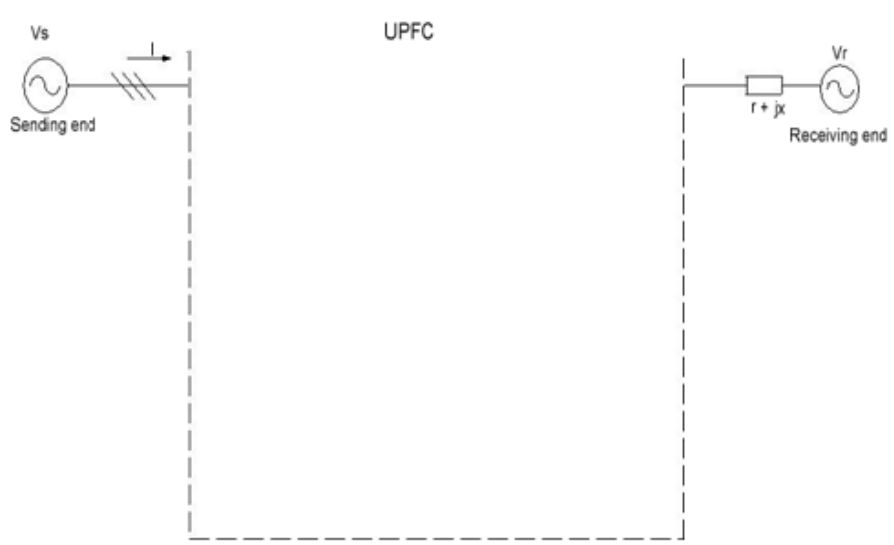

Fig.1 Basic Functional Scheme of UPFC

The series inverter is controlled to inject a symmetrical three phase voltage system (Vse), of controllable magnitude and phase angle in series with the line to control active and reactive power flows on the transmission line. So, this inverter will exchange active and reactive power with the line. The shunt inverter is operated in such a way as to demand this dc terminal power (positive or negative) from the line keeping the voltage across the storage capacitor Vdc constant. So, the net real power absorbed from the line by the UPFC is equal only to the losses of the inverters and their transformers. The remaining capacity of the shunt inverter can be used to exchange reactive power with the line so to provide a voltage regulation at the connection point [1].

Control of power flow is achieved by adding the series voltage, $\mathrm{V}_{\mathrm{S}}$ with a certain amplitude, and phase shift, $\varphi$ to $\mathrm{V}_{1}$. This will gives a new line voltage $\mathrm{V}_{2}$ with different magnitude and phase shift. As the angle pvaries, the phase shift $\delta$ between $V_{2}$ and $V_{3}$ also varies. Fig.2 shows the single line diagram of the UPFC and phasor diagram of voltage and current.

$$
\begin{aligned}
& \mathrm{VV} \\
& \mathrm{X}
\end{aligned} \frac{\mathrm{QVV}}{\mathrm{X}}
$$

With the presence of the two converters, UPFC not only can supply reactive power but also active power. The equation for the active and reactive power is given as follows:-

$$
\begin{array}{ll}
\mathrm{P} \quad \frac{\mathrm{V}}{\mathrm{V}} \sin \delta \\
\\
\mathrm{Q} \quad \mathrm{V} \mathrm{V} \cos \delta & 1
\end{array}
$$

Although the UPFC improves the power flow in the transmission line, its presence imposes number of problems including distance protection. The apparent impedance seen by a distance relay is influenced greatly by the location and parameters of UPFC besides the fault resistance magnitude of the arc in case of a ground fault. If the impedance seen by a relay is lower or higher than the actual line impedance, the distances relay either over reaches or under reaches. Thus an adaptive relay setting of the distance protection is required to cope up with the problems of over reach or under reach [9].

\section{Fault Analysis And Results}

The fault analysis has the main purpose of understand the temporal behavior of line current and voltage at one end of the transmission line at different fault location and compensation levels by using impedance trajectory. The results provided are needed to determine particular traces helpful to discriminate between fault events occurring before or after the UPFC. Table 1 shows the general data of the test system.

The transmission line is simulated in two ways and for single phase - ground fault (A-G); in the first case compensation is not providing with the line and fault is created in the different location from the source end. Fig. 3 shows the result of case 1.

And in second case compensation is providing with the transmission line and fault is created in the line at a distance of $150 \mathrm{~km}$ and $50 \mathrm{~km}$ from the source i.e. after the UPFC and before the UPFC. Fig. 4 shows the result of case 2. In Fig 3\& 4; the Mho characteristic shows the effect of the UPFC when it is connected in the transmission line. 


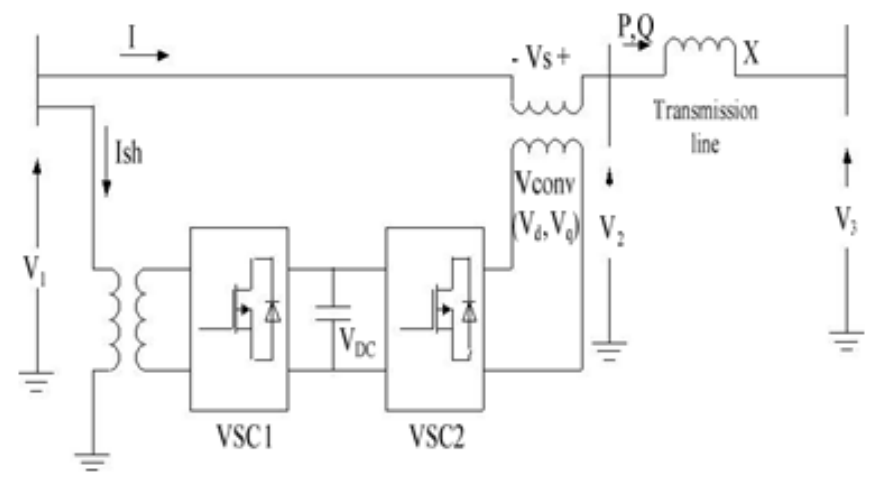

(a)

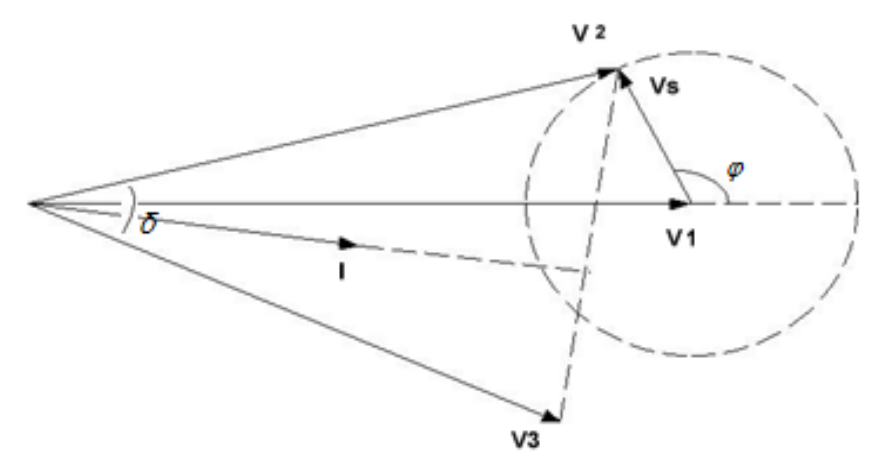

(b)

Fig. 2 (a) Single Line Diagram of UPFC and (b) Phasor Diagram of Voltage and Current

Table I. General Data of the Test System

\begin{tabular}{|l|l|}
\hline Element & Value \\
\hline Generator 1,2 & $100 \mathrm{MVA}$ \\
\hline $\mathrm{kV}$ Generator V1,V2 & $230 \mathrm{kV}$ \\
\hline & \\
\hline Frequency & $50 \mathrm{~Hz}$ \\
\hline & \\
\hline Source Impedance & \\
\hline & \\
\hline $\mathrm{Zs}_{1}$ & $0.238+5.72 \mathrm{j} \Omega$ \\
\hline $\mathrm{Zs}_{0}$ & $2.738+10 \mathrm{j} \Omega$ \\
\hline $\mathrm{ZR} 1$ & $0.238+6.19 \mathrm{j} \Omega$ \\
\hline & \\
\hline $\mathrm{ZR} 0$ & $0.833+5.12 \mathrm{j} \Omega$ \\
\hline & \\
\hline$\delta$ & 15 \\
\hline & \\
\hline Transmission Line Length & $200 \mathrm{Km}$ \\
\hline & \\
\hline Line R1, R0 & $0.0275,0.275 \Omega / \mathrm{Km}$ \\
\hline & \\
\hline Line L1,L0 & $1.35,3.75 \mathrm{mH} / \mathrm{Km}$ \\
\hline & \\
\hline Line C1,C0 & $9.48,6.711 \mathrm{nF} / \mathrm{Km}$ \\
\hline & \\
\hline & \\
\hline & \\
\hline & \\
\hline & \\
\hline &
\end{tabular}

In Fig. 4 (a) are for the fault after the UPFC and by comparing this to the Fig.3 (a), it shows that how the apparent impedance seen by the relay is change and in Fig.4 (b) \& Fig.3 (b) have same impedance characteristic, the fault after the UPFC i.e. $50 \mathrm{~km}$ from the source has same impedance characteristic as in the transmission line which do not have the UPFC compensation. This describes how the apparent impedance changes, when the UPFC is incorporated with the transmission line. 


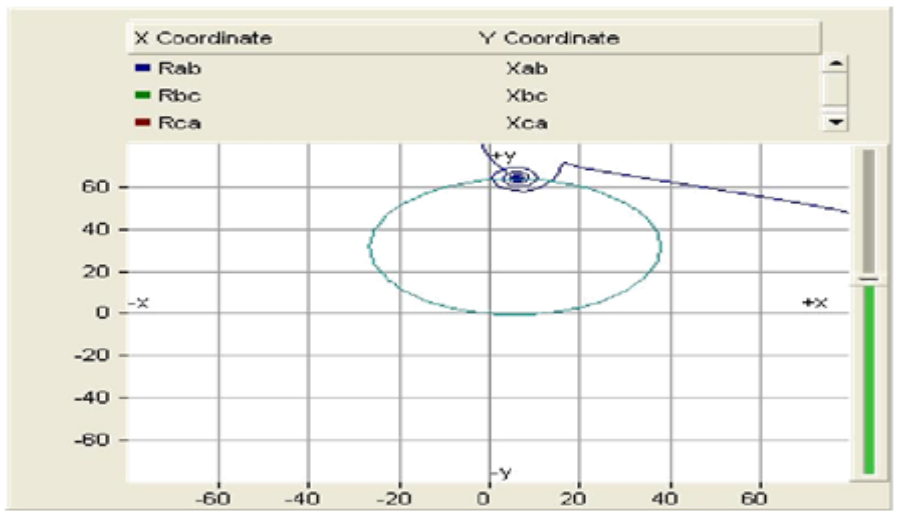

(a)

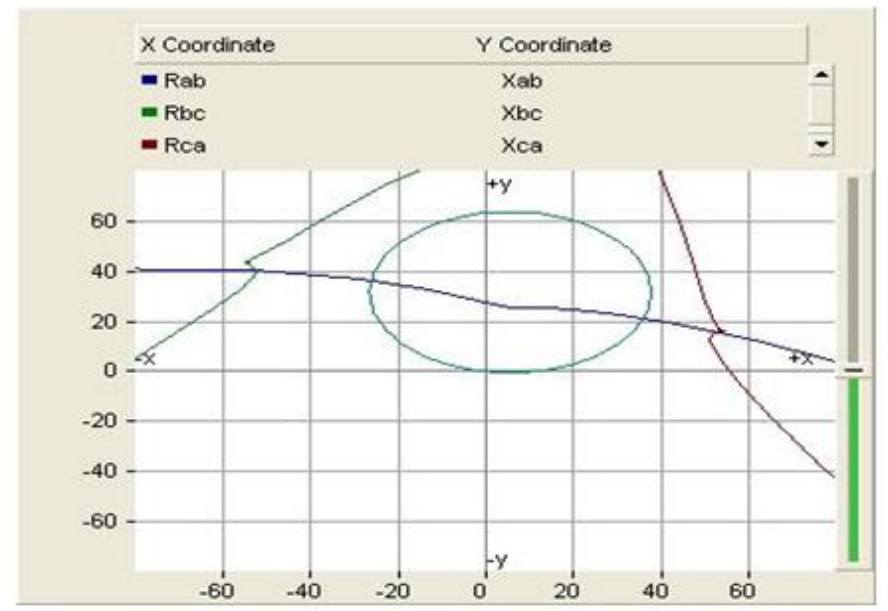

(b)

Fig. 3 Mho Characteristic for A-G Fault at (a) $150 \mathrm{~km}$ (b) $50 \mathrm{~km}$ from Source End

By using the above simulated result, the change in the apparent impedance seen by the distance relay is shown in Fig 5. when the UPFC is connected at the mid point of the transmission line then apparent impedance seen by the relay is same for the fault, which occour before the UPFC. For fault after the UPFC, the change in the apparent impedance is much higher then the fault before UPFC. Fig 5 (a) shows, the percentage change in the apparent impedance for single phase - ground fault, and Fig 5 (b) \& (c) are the result for phase-phase fault $\&$ three phase fault respectively.

These result shows that how much distance relay is affect by the prasence of the UPFC in transmission line. this huge apparent create very big problem to the convetional distance relay and alsofor the power system stability. For solving this problem there is method which addressed that how we overcome this problem. As the distance of the fault is increases the \% change in the apparent impedance seen by relay is increase repidly.this is divert the main objective of installing the UPFC in the transmission line.

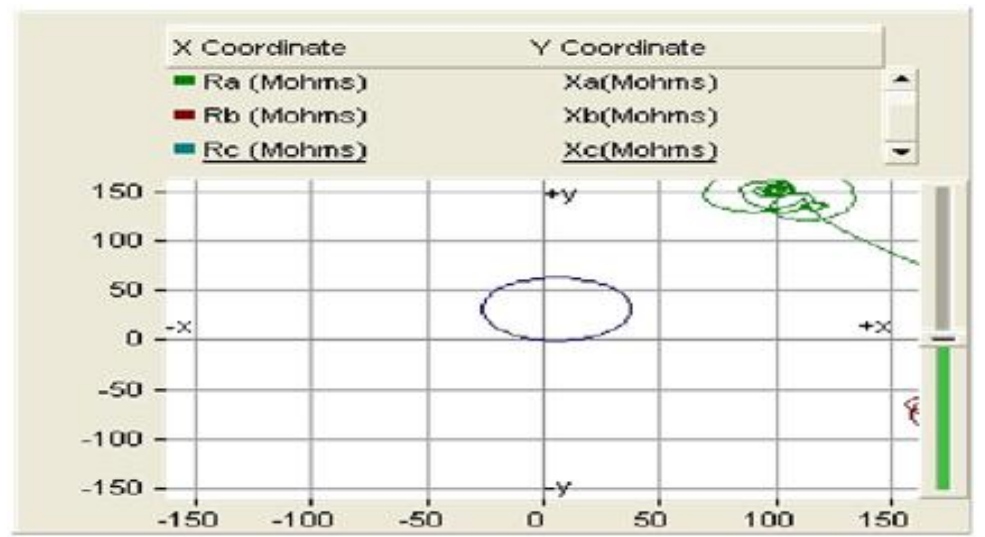

(a) 


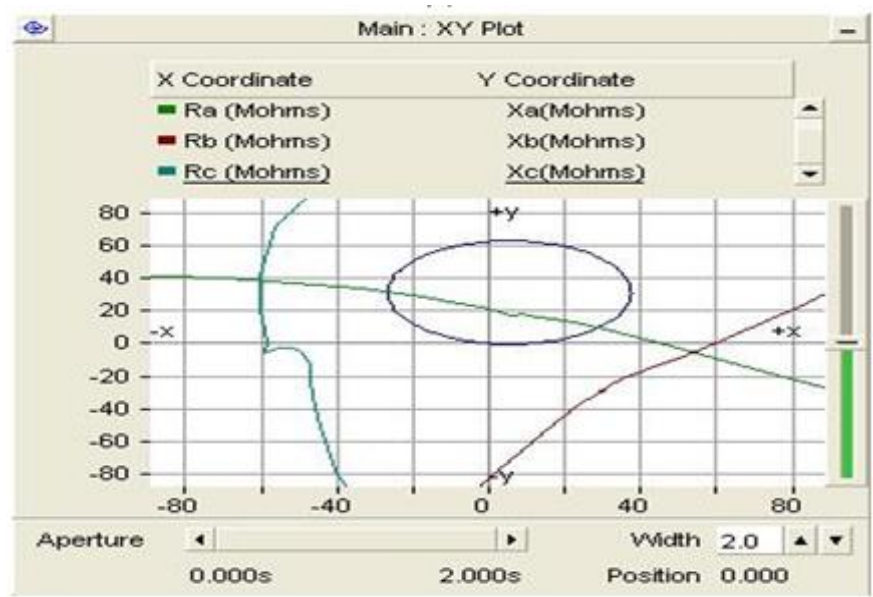

(b)

Fig. 4 Mho Characteristic for A-G Fault at (a) $150 \mathrm{~km}$ ie. After UPFC (b) $50 \mathrm{~km}$ i.e. before UPFC

\section{Conclusion}

Higher the compensation level and closer the fault to the UPFC greater the difficulties for a distance relay to determine the fault location. This is because most of the reactance of the portion of the faulted line is cancelled, so the total equivalent impedance of the non faulted section of the line is smaller for compensated systems than for non-compensated system. In other words, the electric length of the compensated line looks shorter than the non-compensated one. The fault analysis carried out was fruitful in providing information useful to establishing the criteria for implementing the new algorithm The simulation result shows the impact of UPCF on the relay characteristic, the impact on the performance of a distance relay is significantly higher when the full UPFC is operated instead of without UPFC because the Mho characteristic is not same as the Mho characteristic of distance rely of transmission line without UPFC. When comparing the results at different fault location from UPFC, there is a tendency for distance relay to under reach more in case of UPFC. The result shows that there is a basic problem of protection of transmission line when the UPFC is connected in the transmission line or in power system network.

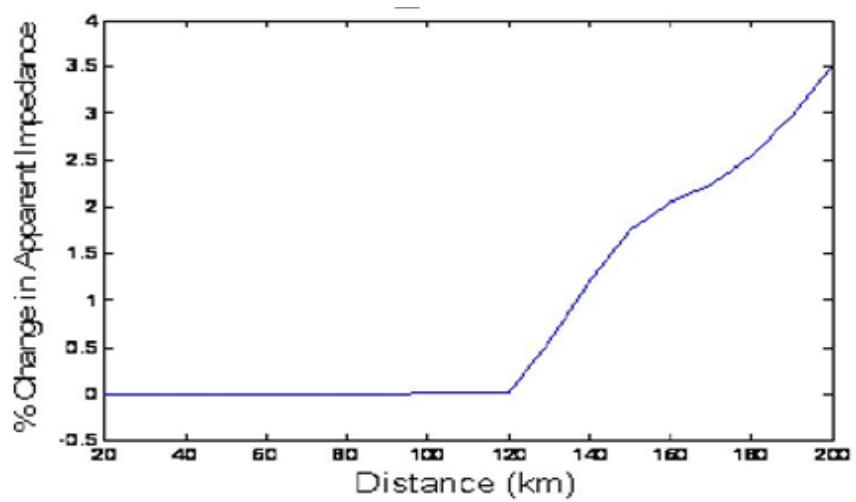

(a)

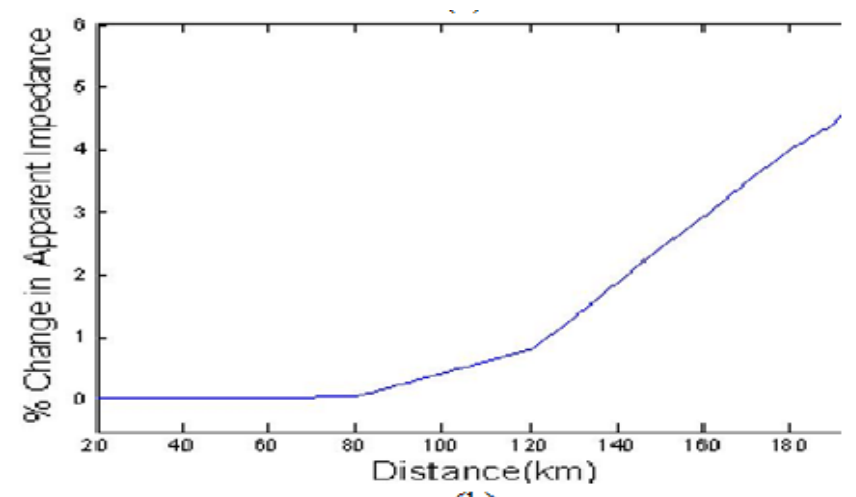

(b) 


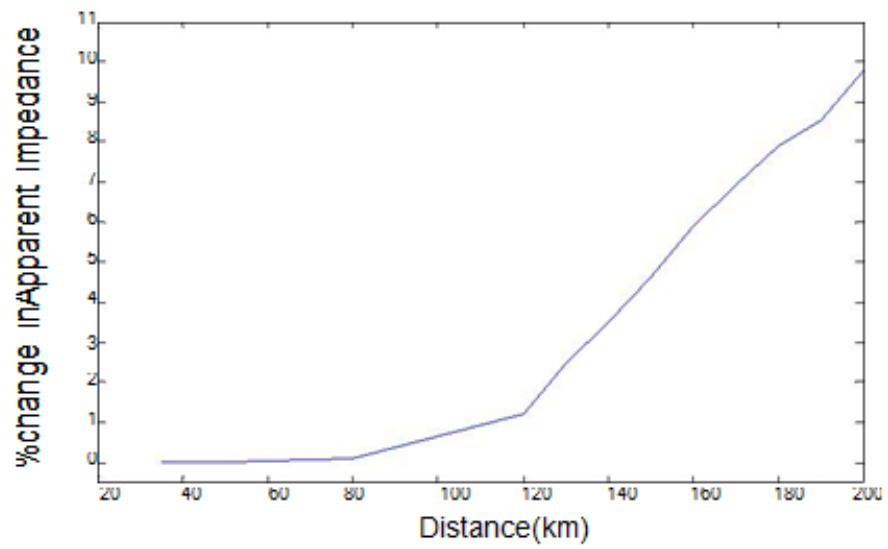

(c)

Fig. 5 Percentage Change in Apparent Impedance for (a) Single Phase to Ground Fault (b) Phase-Phase Fault (c)Three Phase fault

\section{References}

[1] N. G. Hingorani and L. Gyugyi, "Understanding FACTS Concepts and Technology of Flexible AC Transmission Systems", IEEE Press, 2000.

[2] K.R.Padiyar,"FACTS Controller In Power Transmission and Distribution" published by New age International limted,2008.

[3] M. Adamiak and R.Patterson, "Protection requirements for flexible AC transmission system," in Proc.CIGRE, Paris, France 1992

[4] K. El-Arroudi, G. Joos, D.T. McGillis, "Operation of Impedance Protection Relays With the STATCOM" IEEE Trans. on Power Delivery, Vol.17, No.2, pp.381-387, April 2002.

[5] Xiaoyao Zhou, Haifeng Wang, R.K. Aggarwal, Beaumont "Performance Evaluation of a Distance Relay as Applied to a Transmission System with UPFC" IEEE Trans. on Power Delivery, Vol.21, No. 3, pp.1137-11476, July 2006.

[6] P. K. Dash, A. K. Pradhan, Ganapati Panda, and "Adaptive Relay Setting for Flexible AC Transmission Systems (FACTS)" IEEE Trans. on Power Delivery, Vol.15, No.1, January 2000.

[7] Fadhel A. Albasri, Tarlochan Singh Sidhu, Rajiv "Performance Comparison of Distance Protection Schemes for ShuntFACTS Compensated Transmission Lines" IEEE Trans. On Power Delivery, Vol.22, No. 4, October 2007.

[8] Javad Sadeh, N. Hadjsaid, A. M. Ranjbar, and R. Feuillet “Accurate Fault Location Algorithm for Series Compensated Transmission Lines" IEEE Trans. on Power Delivery, Vol.15, No. 3, July 2000.

[9] L. Xu and V.G. Agelidis, "Flying Capacitor Multilevel PWM Converter Based UPFC', IEE Proc. Of Electronic Power Application, Vol. 149, No. 4, 